\title{
Um SUS para a Amazônia: contribuições do pensamento de Boaventura de Sousa Santos
}

\author{
A Unified Health System (SUS) for the Brazilian Amazon: \\ contributions of the social theory of Boaventura de Sousa Santos
}

Michele Rocha El Kadri (http://orcid.org/0000-0002-7179-4755) ${ }^{1}$

Carlos Machado de Freitas (http://orcid.org/0000-0001-6626-9908) ${ }^{2}$

${ }^{1}$ Instituto Leônidas e Maria Deane, Fundação Oswaldo Cruz. Rua Teresina 476, Adrianópolis. 69.057-070. Manaus AM Brasil. michele.kadri@fiocruz.br

${ }^{2}$ Escola Nacional de Saúde Pública Sergio Arouca. Fundação Oswaldo Cruz. Rio de Janeiro RJ Brasil.

\begin{abstract}
The Brazilian Amazon is far from being a homogeneous area. There are various forms of occupation and livelihood in the area that have in common a daily life deeply marked by interaction with the natural environment. Highlighting some elements of Boaventura de Souza Santos' social theory, this paper discusses how the problem of a linear timeline and the dominant scale in hegemonic thinking has served to leave the Amazonian territories outside the scope of inclusion in public health planning. It further points out that in order to engender 'post-abyssal' thinking in the SUS for the region inevitably requires the redefinition of the economic role of the region and an inclusive social development framework with the Brazilian Amazon, and not irrespective of it. Lastly, the possibility that the local SUS should be based on a three-pronged approach, not exclusively urbancentered, which considers its territorial extension, population density and the ways in which access to health services takes place.
\end{abstract}

Key words Health policy, Health planning, Unified Health System, Brazilian Amazon
Resumo A Amazônia brasileira não é um espaço homogêneo, nela subsistem diversas formas de ocupação que em comum têm cotidianos profundamente marcados pela interação com o meio natural. Destacando alguns elementos da teoria social de Boaventura de Souza Santos, o artigo discute como o problema do tempo linear e da escala dominante no pensamento hegemônico vem servindo para invisibilizar os territórios amazônicos na organização das ações públicas de saúde. Aponta ainda que consolidar um SUS pós-abissal na região passa inevitavelmente por uma repactuação do papel econômico e desenvolvimento social inclusivo com a Amazônia, e não apesar dela. Por fim, reflete se a construção do SUS local deveria se basear em um tripé, não exclusivamente urbanocentrado, que considere sua extensão territorial, densidade populacional e vias pelas quais os fluxos de acesso aos serviços de saúde acontecem.

Palavras-chave Política de saúde, Planejamento em saúde, Sistema Único de Saúde, Amazônia 


\section{Introdução}

Amazônia ribeirinha, Amazônia de fronteira, Amazônia indígena, urbana, de assentamentos, do agronegócio, do narcotráfico, Amazônia preservada, Amazônia super explorada. Longe de ser um espaço homogêneo, na Amazônia brasileira subsistem diversas formas de ocupação que em comum têm cotidianos marcados tão profundamente por elementos naturais que orientam a organização da vida, entre os quais o regime das águas, que confere grande singularidade à região. Uma análise mais cuidadosa em qualquer campo do conhecimento deve considerar a historicidade e a dinâmica territorial peculiar dessa região. A proposta do texto é, a partir de alguns elementos da teoria social de Boaventura de Souza Santos, pensar a região para além do pensamento hegemônico que, via de regra, vem produzindo leituras no campo da saúde que a localizam como lugar da doença, da incipiência de processos organizativos, do vazio e da vulnerabilidade, e que desconsideram tamanha heterogeneidade.

Inicialmente, apresentamos alguns elementos do pensamento desse autor que podem contribuir na construção de uma perspectiva pós-colonial e pós-extrativista para a região a partir de uma visão interdisciplinar, positiva e propositiva como deve ser o próprio campo da saúde coletiva. Destacam-se duas questões, o problema do tempo linear e da escala dominante, para discutir como servem para invisibilizar os territórios amazônicos no planejamento das ações públicas de saúde. Por fim, apontamos para a ideia de que consolidar o SUS na região passa inevitavelmente por uma repactuação do papel econômico e do desenvolvimento social inclusivo, com e para as pessoas que aqui constroem suas histórias e dão sentido a este lugar.

Essa discussão sobre o papel da Amazônia no cenário de desenvolvimento nacional nada tem de local, considerando que ela é essencial na irrigação das terras agrícolas que garantem a exportação dos principais produtos do país, assim como o balanço hídrico das bacias que fornecem água a milhões nas cidades no Sul e Sudeste brasileiro. Também não é irrelevante sua importância na regulação do clima global. As reflexões apresentadas ampliam a discussão e apontam como o modelo de desenvolvimento econômico e social atual concorre para aprofundar as desigualdades com a marca cartográfica abissal que separa o Norte e o Sul do país.

\section{A produção de ausências \\ e o pensamento pós-abissal}

Segundo Boaventura de Souza Santos ${ }^{1}$, o colonialismo que separava o mundo entre o moderno, tecnológico e desenvolvido ao Norte da linha do Equador e o primitivo, atrasado e bárbaro ao Sul nas colônias europeias nos séculos XV e XVI "continuam a subsistir estruturalmente no pensamento hegemônico e permanecem constitutivo das relações políticas e culturais excludentes mantidas no sistema mundial contemporâneo". Sob tal argumento, o autor identifica que as linhas cartográficas abissais que demarcavam o Velho e o Novo Mundo se expressam ainda hoje, por exemplo na história "oficial" do mundo contada a partir da explicação ocidental, sobre a única verdade válida estar contida no conhecimento científico ou no modo hegemônico capitalista de produção. O que quer que se produza fora desses parâmetros é ignorado, desqualificado, são "experiências desperdiçadas"2 que a atual racionalidade produz como ausentes, mas que por certo poderiam estar presentes. A linha abissal não foi apagada com o fim da ocupação colonial nos territórios, hoje assume novas formas que criam racismos, xenofobias, epistemicídios, entre outras formas de exclusão ${ }^{3}$. O pensamento pós-abissal é, portanto, aquele que considera que outras formas alternativas de conhecimentos e práticas construídas localmente a partir da experiência e histórias dos lugares e das pessoas são válidas e possíveis para além do conhecimento dominante.

$\mathrm{Na}$ validação de processos contra-hegemônicos, ele propõe aquilo que chama de sociologia das ausências ${ }^{3}$ como forma de reconhecer as sabedorias e fazeres que o pensamento dominante invisibiliza, é tornar presente no discurso e na prática tudo aquilo que fora produzido ativa e intencionalmente como inexistente, invisível frente à leitura hegemônica universal.

Para o autor, produz-se ausências como resultado de cinco "monoculturas". A primeira é a "monocultura do saber e do rigor científico", que desacredita da prática social e do conhecimento popular que não se curvam à objetividade e ao método da ciência ocidental. A segunda é a "monocultura do tempo linear", que indica que a história de toda a humanidade teria pretensamente uma única direção na linha do desenvolvimento, na qual países centrais estariam na dianteira e todo o resto ainda estaria por fazer o mesmo caminho. A terceira forma de criar ausência é pela 
"naturalização das diferenças", que aponta para uma hierarquização étnica, racial, sexual e social, segundo as quais as desigualdades seriam naturais. Já pela "monocultura da escala dominante", desconsidera-se o contexto no qual os fenômenos acontecem, de modo que o global, universal, é hegemônico, e tudo o que é de escala local é menor ou mesmo inválido. Por fim, “a monocultura do produtivismo capitalista” declara moderna a técnica que reproduz coisas, conhecimentos, práticas em maior escala e no menor tempo possível, fora disso, outra forma de produção não teria grande valor.

A sociologia das ausências propõe contrapor a cada monocultura uma ecologia de forma a disponibilizar experiências que se encontram invisíveis, reconhecendo que outros saberes são possíveis. A “ecologia dos saberes” não implica desacreditar o saber científico, mas posicioná-lo num leque mais amplo de saberes em que outros também são possíveis. A "ecologia das temporalidades" considera que há outros tempos, além do tempo linear, como os ciclos da natureza ou o tempo dos antepassados de culturas indígenas ou africanas que continuam sempre contemporâneos. A “ecologia do reconhecimento" propõe descartar hierarquias que sustentam a dominação colonial. Diferenças são naturais, desigualdades não. A quarta ecologia é a da "transescala", que sugere a possibilidade de articulação entre realidades locais e globais, nunca descontextualizando análises e ações do lugar em que ocorrem. A quinta é a "ecologia das produtividades" como uma alternativa ao modo de produção hegemônico, valorizando a organização de sistemas cooperativos, solidários e ambientalmente mais sustentáveis.

Neste trabalho destacamos dois desses conceitos para aprofundar reflexões importantes que ajudam a apontar como a realidade amazônica tem estado com frequência ausente de diretrizes que orientam a construção do SUS. A primeira é a racionalidade do tempo linear, que é diferente do tempo vivido pelas comunidades amazônicas que em grande medida têm suas vidas orientadas pela sazonalidade do ciclo das águas. O segundo ponto é o problema da escala que influencia naquilo que é visto ou invisibilizado numa política universal como o SUS. Essas questões oferecem elementos relevantes para entender como a dinâmica desse território desafia uma outra lógica de organização do sistema de saúde, e que, se bem acolhida pelo planejamento, pode ajudar na construção de um SUS pós-abissal com e para a região.

\section{O tempo linear e o tempo da Amazônia das águas}

A marcação cronológica do tempo é uma invenção humana. O que existe é uma sucessão de fatos e de encontros que nos permite cumprir um conjunto de ações indispensáveis à sobrevivência e produção humanas. No entanto, o tempo do-

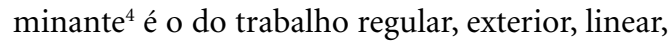
acelerado e homogêneo, que determina as regras de organização da vida a partir das atividades produtivas.

Contudo, na Amazônia das águas o tempo é ditado pelos ciclos de enchente e vazante dos rios. Embora os grandes projetos instalados na região a partir de 1960 tenham estimulado a ocupação ao longo das rodovias construídas nas porções Sul, Sudoeste e Leste da região, ainda é ao longo dos rios que há maior concentração populacional, incluindo as metrópoles regionais ${ }^{5}$. O regime hidrológico que tão marcadamente singulariza a região afeta não somente as populações que vivem à margem dos rios, mas os residentes em terra firme que têm seus ritmos de produção influenciados pela sazonalidade fluvial e a perenidade ou não dessas águas, pois disso depende a escoamento de sua produção agrícola e as chuvas que irrigam as lavouras. Mesmo em cidades médias ou espaços metropolitanos com uma dinâmica mais urbana, o rio comanda o fluxo de abastecimento a essas cidades, sendo também importante para atividades de turismo e lazer. Assim, apesar da região de várzea compreender cerca de 3\% do total da superfície da Amazônia brasileira, sua importância é inversamente proporcional à sua dimensão territorial ${ }^{6,7}$

A várzea, numa definição geral, é uma planície aluvial formada por uma rede de rios que está sujeita, parcial ou totalmente, a inundações sazonais, sendo o seu solo renovado por sedimentos trazidos anualmente pelos rios $^{8,9}$. As atividades de subsistência e produção dependem necessariamente do regime fluvial, cuja sucessão cíclica exige da população constante reordenamento e adaptação. Quando há seca, as casas ficam isoladas pela falta de acesso, obrigando o morador a caminhadas extensas até um porto. Na cheia, é preciso elevar o assoalho das casas com madeiras para subir os móveis e transferir os animais para terra firme ou fazer currais flutuantes. As distâncias diminuem pela possibilidade de uso do transporte fluvial, o que altera também as atividades produtivas. Os lagos são fonte de abastecimento, principalmente do pescado, mas os hábitos alimentares se modificam com a descida da 
água e a fonte de proteína passa do peixe para a carne de caça. As águas mudam a paisagem, árvores somem e aparecem, casas mudam de lugar ou simplesmente desaparecem, as propriedades são aumentadas ou diminuídas pela sedimentação/ erosão deixada pela descida dos rios.

Só há história porque há diferentes formas de se realizar a mobilidade no tempo e no espaço ${ }^{10}$, e na Amazônia as horas e os dias são medidas de distância mais apropriadas do que quilômetros. É o tempo que mede o deslocamento no espaço $^{11}$. Esse deslocamento também depende do nível da água, do tipo de transporte e da potência do motor. Quanto maior a potência, menor é a distância entre os lugares, porém maior é o custo com combustível. O tempo e o espaço são relativizados pelo conjunto dessas variáveis, sendo tudo isso incorporado pela cultura regional quando o tempo passa a ser outra coisa que não a medida do tempo do capital, mas a medida dos ciclos naturais.

Se do ponto de vista do tempo linear essa sazonalidade dificulta a exploração da terra pelo produtivismo capitalista, pois não admite aceleração do tempo das colheitas ou a especialização das culturas agrícolas, por outro lado, do ponto de vista da ecologia das temporalidades, nesse cenário o rio não é obstáculo à produção, pelo contrário. Ele é o elemento que faz conexões, ligações entre pessoas, serviços e instituições, mediando a ação humana nesse território. $\mathrm{O}$ rio não é apenas um limite natural, é lugar de vida e de significados. Por ele, histórias das pessoas, das coisas e da natureza se conectam para a criação do evento.

Se o tempo "dessa amazônia" difere do tempo hegemônico, tornar presente essa temporalidade é pensar que a ação humana, incluindo políticas públicas, também deve ser permeada por essa fluidez e mobilidade. Nesse cenário, parece bastante imprudente, até mesmo excludente, pensar um serviço de saúde que se organize exclusivamente a partir de fluxos terrestres em que usuários se locomovem por meio rodoviário. Cruzar a linha abissal que invisibiliza tal contexto de organização da vida seria organizar um sistema que não segue somente os pontos fixos marcados pela política e pelo planejamento.

Numa perspectiva diferente do tempo da Amazônia das águas, a monocultura do tempo linear vem sistematicamente localizando a região na linha do "atraso", do "primitivo", do "incipiente”, em uma representação unidirecional daquilo que é entendido hegemonicamente como desenvolvido e moderno. No campo da saúde, é preciso estar atento aos limites de análises a partir de um recorte no tempo. Sem a historicidade dos lugares, são limitadas as possibilidades de explicação das causas (que estão num tempo passado) ou apontar soluções pragmáticas (em um tempo futuro). Para tornar presente o tempo amazônico na prática e no discurso é imprescindível que os achados dos inquéritos nacionais retornem ao território e dialoguem com suas histórias e peculiaridades, potencializando assim a construção de alternativas junto com gestores, trabalhadores e comunidades locais na consolidação do Sistema Único de Saúde. Como abordar a integralidade na assistência às pessoas sem abordar a integralidade de seus lugares? E como abordar a integralidade dos lugares sem considerar suas diferenças?

Os lugares são palco das realizações humanas e todos têm sua história marcada por diferentes jogos de poder, internos e externos, que orientam os processos sociais ao longo do tempo ${ }^{10}$. Nas análises globais, mais eficiente do que posicionar as localidades numa etapa mais ou menos "desenvolvida", supondo uma linearidade dos processos, é se apoiar no produto dessa comparação, que pode orientar ações prioritárias focais de modo a aproveitar positivamente as características atuais e as projeções futuras. Experiências e conhecimentos locais (acadêmicos ou populares) podem ensinar um bom caminho para tornar presente o tempo e a história da região em uma ecologia dos saberes.

Produz-se ausência quando se pensa que lugares diferentes estão em tempos diferentes, atrás ou à frente em sentido unidirecional no "desenvolvimento". Isso significa dizer que são realidades simultâneas, mas não contemporâneas. e Como aponta Souza Santos ${ }^{1}$, não se pode "inventar passados para dar lugar a um futuro único e homogêneo".

É preciso não naturalizar os lugares como dados da realidade, ignorando poderes e construções sociais de diferentes grupos que aí se expressam $^{10}$. É preciso pensar o território de modo complexo. Sabendo que a formação histórica e cultural se deu de modo muito distinto entre as regiões do país, é de se esperar que tais diferenças marquem também a implantação do SUS nos diversos cenários brasileiros.

Essas diferenças reforçam a necessidade, para um sistema público que se propõe garantir saúde universal, de primar por uma organização focal capaz de diferenciar processos sociais distintos e planejar ações de modo a responder localmente às demandas ${ }^{12}$. Compreender tais diferenças é fundamental na elaboração de políticas públicas, pois, a depender das decisões tomadas, as inter- 
venções podem tanto atenuar como aprofundar as desigualdades no país ${ }^{13}$. Aqui entramos no segundo ponto que gostaríamos de destacar: o problema da escala.

\section{Monocultura da escala dominante e territorialização da saúde}

No pensamento hegemônico, a escala dominante aponta que realidades locais são menos importantes, pois “o global e universal é hegemônico; o particular e local não conta, é invisível, descartável, desprezível"' . A questão da universalização está sempre presente entre os sanitaristas, gestores e trabalhadores da região que lidam com o desafio de implantar um sistema único em uma região tão diversa dos centros onde as políticas são desenhadas.

Por reconhecer saúde como direito social, um sistema universal organiza sua atuação de modo a responder à necessidade de saúde da população por ele coberta. A contradição presente é que o modelo universalista, ao defender acesso aos bens público como um direito social, não discrimina nem positiva nem negativamente o cidadão, tratando como igual sujeitos que vivem em condições muito distintas. A igualdade fundamenta a estratégia de universalização, ao passo que a equidade orienta a estratégia de focalização ${ }^{14}$. Se por um lado o universalismo tem por base a garantia de direito independentemente de qualquer condição prévia, por outro lado a focalização orienta concentração de recursos em determinadas condições excepcionais ou grupos preferenciais, de maneira que recursos cheguem aos mais fragilizados. Os conceitos não necessariamente se anulam, o sistema pode ser universal mas com uma organização focal. Kerstenetzky ${ }^{15}$ esclarece que a focalização pode ser entendida como "ação reparatória necessária para restituir a grupos sociais o acesso efetivo a direitos universais [...] que teriam sido perdidos como resultado de injustiças passadas". Isso é especialmente importante para países com grandes desigualdades como o Brasil, no sentido de aproximar o direito universal à sua efetiva realização. Segundo a autora, somente um sistema universal é capaz de garantir condições mínimas para a preservação da vida, em especial aos mais excluídos.

Promover ações de saúde específicas e/ou um modo diferenciado de organizar o sistema "nas amazônias" não se trata de uma intervenção residual, típica do modelo assistencialista, mas sim de um modelo adequado para esse espaço, não apenas para corrigir negligências passadas e in- correções presentes, mas acolher a diversidade de conhecimentos e as territorialidades locais.

Insere-se aqui outra discussão de Souza Santos $^{16}$ sobre a cartografia simbólica, que aponta para a construção de um pensamento contra-hegemônico que supere o olhar em pequena escala, na qual estratégias são planejadas, e aumente a escala para melhor análise e emergência de alternativas possíveis construídas pela região. Ações focalizadas (grande escala) poderiam complementar a estratégia universal (pequena escala).

O uso de escala para construção de mapas é uma ferramenta que precisa equilibrar o nível de detalhamento com a funcionalidade que os mapas devem ter, de modo que a distorção inevitável da realidade não signifique necessariamente distorção da verdade. Uma vez que priorizam a representação de uma área maior, ao reduzir a escala os mapas ocultam detalhes que nos permitiriam análises mais pormenorizadas dos lugares. Inversamente, ao aumentar a escala a representação revela a heterogeneidade das experiências locais. A escolha de qual escala usar depende da natureza do fenômeno que se quer analisar. As estratégias devem ser pensadas em pequena escala (nível nacional), enquanto as ações cotidianas, que levam ao sucesso da estratégia, devem ser tomadas na grande escala (nível local) ${ }^{16}$. Entendemos que a questão da escala é especialmente relevante para discutir o quanto análises em pequena escala numa perspectiva global vêm produzindo distorções capazes de homogeneizar a Amazônia apesar de sua extensão territorial e da coexistência de diferentes territorialidades.

Em contraposição à monocultura da escala dominante, que se expressa no universalismo, a ecologia da transescala permitiria a copresença solidária do local e do global. Já apontamos que só um sistema universal reuniria as condições necessárias para promover equidade e, portanto, algum grau de justiça social. Isso não é pouco, mas é preciso também admitir a possibilidade de copresença de estratégias universais em mesmo grau de relevância de ações focalizadas e, ainda, a articulação nesses dois níveis. Nesse sentido, assim como para as epistemologias do Sul não há uma teoria geral capaz de abarcar toda a diversidade das coisas, talvez não haja um SUS universal capaz de abarcar a diversidade dos territórios.

Tão importante quanto considerar as territorialidades locais é dimensionar adequadamente os desafios que a extensão física e o ordenamento territorial da Amazônia impõem à organização do sistema de saúde. Para exemplificar a disparidade das escalas a que as diretrizes nacionais 
devem dar conta, temos o estado do Amazonas, que territorialmente equivale a 15 vezes o estado de Santa Catarina, mas com densidades demográficas de 2,61 hab $/ \mathrm{km}^{2}$ e 73,13 hab $/ \mathrm{km}^{2}$, respectivamente. Em outro exemplo, certamente as questões de saúde que afetam os 40 mil brasileiros de São Gabriel da Cachoeira (0,41 hab/ $\mathrm{km}^{2}$ ), município do Amazonas que faz fronteira com Colômbia e Venezuela e onde três em cada quatro habitantes são indígenas, são diferentes daquelas dos 40 mil moradores de Santa Cecília, concentrados num bairro da região central do município de São Paulo $\left(29,08\right.$ hab $\left./ \mathrm{km}^{2}\right)$. A mesma universalidade deve responder a situações de saúde muito distintas. Não se pode desconsiderar a escala e, principalmente, as diferenças de uso e ocupação do território. Ao comparar realidades tão diversas, quase sempre se elege um centro a partir do qual as diretrizes são pensadas e todo o resto vira periferia. Nessa razão, alguma realidade há de ser invisibilizada.

Trabalhar junto às secretarias locais de saúde nos tem feito pensar numa hipótese que por um lado aponta para a inabilidade das políticas (estratégias macros na pequena escala) para atender satisfatoriamente à necessidade de saúde dessa população, e por outro indica um engessamento organizativo que dificulta a construção e proposição de soluções locais (ações territorializadas na grande escala).

Ainda que a descentralização já proposta desde a criação do SUS seja uma tentativa de aproximar as ações aos territórios, na prática permanece o desafio de definir diretrizes capazes de responder a demandas que a diversidade territorial brasileira impõe. Vimos que grande parte da Amazônia, em especial a porção central e ocidental, tem particularidades importantes: fluxos que não se dão por via terrestre, mas fluvial; baixa densidade demográfica que por vezes não justifica alocação de equipamentos e profissionais exclusivamente pelo critério demanda por assistência; e uma extensão territorial que desafia a construção de redes de atenção acessíveis. Dada a extensão territorial de muitos municípios amazônicos com extensão territorial maior do que alguns estados do país e a baixa densidade demográfica, fica evidente que a organização do sistema de saúde pensado considerando a priori a interligação terrestre e a contiguidade dos territórios não há de fazer muito sentido quando se fala de territórios amazônicos.

\section{Repactuação do papel da região no cenário social e econômico do país}

É inevitável não associar essa discussão ao modelo de desenvolvimento adotado pelo país e como a região está inserida nesse plano. Ainda hoje, no Brasil, dos dez produtos mais exportados, oito são produtos básicos (agrícolas) ou semimanufaturados (açúcar e celulose) ${ }^{17}$. Vemos que pouco mudou desde as relações colonialistas Norte-Sul do século XVI. Nesse cenário, os discursos sobre a Amazônia de "terras inabitáveis", "lugares inóspitos" e "estradas que ligam nada a lugar nenhum", ou alguns termos mais técnicos como "vazio demográfico", ainda são vigentes. Além de apontar ausências sobre as amazônias, localizam a região no plano global: onde nada há, tudo pode ser feito. Isso reforça a região como fronteira de expansão mercantil e/ou potencial fornecedora de matérias-primas.

Em nome do desenvolvimento das cidades não para todos -, invisibiliza-se direitos de indígenas, quilombolas, de posseiros ou ribeirinhos; nesse "desenvolvimento" não cabem esses povos. Qual racionalidade há em viver num território que só pode ser "útil" parcialmente durante o ano? Ou, ainda, por que há pessoas que insistem em viver em lugares onde não há serviços públicos? Por trás disso, revela-se o pensamento abissal que as pessoas estariam no lugar errado. $\mathrm{O}$ modelo de desenvolvimento ambientalmente predatório e socialmente excludente ${ }^{18}$ tem levado a violações de direitos recorrentes das populações "atrasadas" que aí residem. Danos concretos e/ou ameaças sofridas vêm tanto pela via da expropriação direta da terra quanto pela inviabilização da vida nesses lugares via degradação ambiental, com contaminação de rios, solos e extrativismos predatórios. Todos os nove estados que compõe a Amazônia Legal registraram algum conflito no campo em 2017, com destaque para Maranhão, Rondônia, Pará e Tocantins. Mais alarmante é que não raro os casos ocorrem com conivência do poder Judiciário, que concede legalidade a terras griladas, por exemplo ${ }^{19}$. Mesmo em regiões com famílias já assentadas, a desassistência se expressa na precariedade de vias para escoamento da produção, dificuldade para acesso a crédito e ausência de serviços como saúde e educação para qualificação da produção.

Além dos conflitos de terra que se concentram nos altos relevos de terras firmes, há a ameaça que atinge direta e violentamente os ribeirinhos: a construção de grandes barragens que alteram de maneira irremediável o ciclo de 
enchente e vazante dos rios, assim como o curso das águas fluviais. Belo Monte, no Rio Xingu, ou o Complexo de Tapajós (composto por nove usinas), no rio de mesmo nome no Pará, são algumas das dezenas de hidrelétricas planejadas/ construídas na Amazônia que, além de questões ambientais, têm custos sociais, como o aumento da violência, que não entram na conta da geração de energia para abastecer mercados "desenvolvidos" do Sudeste brasileiro ${ }^{20}$.

Tais conflitos só existem exatamente porque no território há atores presentes que divergem desses interesses externos ao lugar. Há, portanto, muita presença! Nessa discussão, a distinção em três grandes macrorregiões sobre as quais deveriam incidir políticas diferenciadas, como proposta por Bertha Becker ${ }^{21}$, ajuda a reduzir a escala e a aproximar estratégias macros do território. A primeira é a consolidação de áreas produtivas de Mato Grosso, Tocantins e Sul do Pará com políticas que não aumentem de depredação. A segunda é região de Amazônia central, abrangendo a maior parte do Pará, e o corredor rodoviário Porto Velho-Manaus-Venezuela, acelerando políticas conservacionistas que respeitam população e dinâmicas já estabelecidas. A terceira é a Amazônia Ocidental, cujas terras ainda são domínios da natureza, portanto com maior potencial para invenção de um modelo de desenvolvimento sustentável para as comunidades que aí vivem. Em qualquer dessas “amazônias", cabe inquestionavelmente uma construção que inclua seus povos e a biodiversidade, repactuando seu papel na economia brasileira para além de simples reserva energética e mineral ou fronteira de expansão agrícola $^{18}$.

Não se trata de um discurso radical contrário ao desenvolvimento, mas de apontar como presente e legítima a luta de ter no Brasil uma matriz de desenvolvimento que garanta direitos e justiça socioambiental para assistir às populações afetadas $^{22}$. Descolonizar o pensamento é construir um outro desenvolvimento, que não seja uma prática extrativista e que seja com e para os territórios. A saúde como política de abrangência nacional não se ausenta desse debate. Apontamos aqui alguns elementos que exemplificam como o SUS não raro tem sido construído hegemonicamente a partir de uma racionalidade diferente da realidade amazônica. Assim, construir um SUS pós-abissal na Amazônia passa por considerar que os atores locais não são apenas portadores de uma "opinião", mas sim de um conhecimento real e válido, e como sujeitos participativos na cons- trução das intervenções de saúde, e não só objeto delas. De tal modo, abre-se a possibilidade da copresença de saberes, e também de ignorâncias, dos dois lados da linha abissal.

A singularidade desse território oferece ao SUS a possibilidade de combinar ações gerais e específicas, com meso e micropolíticas diferenciadas nos diversos territórios da Amazônia, "articulando estratégias para o desenvolvimento, proteção social e saúde" 23 . Fluxos que não se dão necessariamente por estradas, densidade populacional e extensão territorial são três questões centrais no planejamento de serviços de saúde na Amazônia.

\section{Conclusão}

O pensamento abissal, que evidencia a dominação econômica, política e cultural de uns lugares em detrimento de outros, sustenta o discurso hegemônico que cria ausências onde na verdade há muitas presenças. A linha que coloca a Amazônia no lugar do atraso em uma hierarquização de saberes, tempo e escala tem produzido injustiças e desastres recorrentes, resultantes de intervenções inadequadas, públicas e/ou privadas, em função do desconhecimento, intencional ou não, desse lugar.

Para que a universalização do SUS produza redução de desigualdades, garantindo saúde como condição básica para o desenvolvimento na Amazônia, é preciso aumentar a escala de análise e focalizar alternativas mais coerentes com o lugar. Destacamos aqui o desafio peculiar para a gestão local de consolidar o sistema em um território de tamanha extensão territorial, com dinâmica de ocupação não urbano-centrada e com fluxos que não se dão invariavelmente por via rodoviária.

Enquanto persistir o não reconhecimento desse território em toda a sua história, seus ecossistemas e suas culturas, não será possível construir uma alternativa pós-abissal que vença a exclusão que o tem mantido do lado de lá da linha. Inovação tecnológica que gere valor para a biodiversidade, ciência que reduza iniquidades, ecologia de saberes que compartilhem conhecimentos (e também ignorâncias) podem apontar potenciais soluções. Discutir a preservação da Amazônia é importante, mas alternativas econômicas que impactam diretamente as condições de vida e a saúde daqueles que aqui residem é o debate fundamental a fazer. 


\section{Colaboradores}

MR El Kadri trabalhou na concepção, revisão e redação final do manuscrito. CM de Freitas participou das discussões, da revisão crítica e da aprovação final do manuscrito.

\section{Referências}

1. Santos BS. Para além do pensamento abissal: das linhas globais a uma ecologia de saberes. Novos Estud CEBRAP. 2007; (79):71-94.

2. Santos BS. Renovar a teoria crítica e reinventar a emancipação social. São Paulo: Boitempo Editorial; 2007.

3. Santos BS. Para uma sociologia das ausências. Jornal de Letras, Artes e Ideias [periódico na Internet] 2017. [acessado 2019 Abr 11]. Disponível em: http://saladeimprensa.ces.uc.pt/index.php?col=opiniao\&id=17352\#.XAfFmWhKjIV.

4. Oliva-Augusto MH. Tempo, indivíduo e vida social. Cienc Cult 2002; 4(2):30-33.

5. Sathler D, Monte-Mór RL, Carvalho JAM. As redes para além dos rios: urbanização e desequilíbrios na Amazônia brasileira. Nova Econ 2009; 19(1):11-39.

6. Ab’Sáber AN. Amazônia: do discurso à práxis. São Paulo: Edusp; 2004.

7. Jardim CM. Do rural ao urbano: abordagens sobre as mudanças nos padrões alimentares de moradores de áreas de assentamentos rurais do Amazonas [tese]. Manaus: Universidade Federal do Amazonas; 2018.

8. Fraxe TJP. Homens anfibios: etnografia de um campesinato das águas. São Paulo: Annablume; 2000.

9. Witkoski AC. Terras, florestas e águas de trabalho: os camponeses amazônicos e as formas de uso de seus recursos naturais. Manaus: Editora da Universidade Federal do Amazonas; 2007.

10. Santos M. Técnica, espaço, tempo: globalização e meio técnico-científico-informacional. São Paulo: EDUSP; 2008.

11. Kadri MR, Lima RT, Schweickardt JC. Território e políticas de saúde na Amazônia: diálogo necessário. In: Seminário Internacional de Determinantes Sociais da Saúde (no prelo). Manaus; 2017.

12. Giovanella L, Mendoza-Ruiz A, Pilar A de CA, Rosa MC da, Martins GB, Santos IS, Silva DB, Vieira JML, Castro VCG, Silva PO, Machado CV. Sistema universal de saúde e cobertura universal: desvendando pressupostos e estratégias. Cien Saude Colet 2018; 23(6):1763-1776.

13. Brito F. Transição demográfica e desigualdades sociais no Brasil. Rev Bras Estud Popul 2008; 25(1):5-26.

14. Cardoso AJC. Políticas de saúde: universalizar ou focalizar é a questão? In: Alves SMC, Delduque MC, Neto ND, organizadores. Direito sanitário em perspectiva. Brasília: ESMPU/Fiocruz; 2013. p. 333.

15. Kerstenetzky CL. Políticas Sociais: focalização ou universalização? Braz J Polit Econ 2006; 26(4):564-574.

16. Santos BS. Uma cartografia simbólica das representações sociais: prolegômenos a uma concepção pós-moderna do direito. Rev Crit Cienc Sociais 1988; (24):139-172.
17. Ministério da Economia, Comércio Exterior, Indústria e Serviços. Comércio Exterior Brasil (Geral) [documento na Internet]; 2018. [acessado 2019 Abr 11]. Disponível em: http://www.mdic.gov.br/comercio -exterior/estatisticas-de-comercio-exterior/comexvis/frame-brasil.

18. Aguiar D. A favelização da Amazônia e a necessidade de repactuar o papel da floresta na economia do século XXI [página na Internet]; 2018. [acessado 2019 Mar 26]. Disponível em: http://dssbr.org/site/entrevistas/a-favelizacao-da-amazonia-e-a-necessidade-de-repactuar-o-papel-da-floresta-na-economia-do-seculo-xxi/.

19. Comissão Pastoral da Terra. Atlas de conflitos na Amazônia [página na Internet]; 2017. [acessado 2019 Abr 11]. Disponível em: https://www.cptnacional.org.br/ publicacao?task $=$ download.send \&id $=14066 \&$ cati$\mathrm{d}=76 \& \mathrm{~m}=0$

20. Rainey SJ, Rainey MCA. Perspectivas ribeirinha sobre os impactos da construção de usinas hidrelétricas no rio Madeira em Rondônia. Rev Fr-Bras Geogr 2016; 29.

21. Becker BK. A Amazônia e a política ambiental brasileira. In: Santos M, organizador. Território, territórios - ensaios sobre o ordenamento territorial. Rio de Janeiro: Lamparina; 2007. p. 21-40.

22. Gagnon R, Joca P, Kahwage Y, Mascolo-Fortin É, Nadeau-Farley A, Pierre L, Potes D. Energia, para quem e por quê? Comitê para os Direitos Humanos na América Latina (CDHAL); 2017 p. 24.

23. Viana ALD, Machado CV, Baptista TWF, Lima LD, Mendonça MHM, Heimann LS, Albuquerque MV, Iozzi FL, David VC, Ibañez P, Frederico S. Sistema de saúde universal e território: desafios de uma política regional para a Amazônia Legal. Cad Saude Publica 2007; 23(Supl.):117-131.

Artigo apresentado em 20/08/2019

Aprovado em 15/11/2019

Versão final apresentada em 17/11/2019

Editores-chefes: Romeu Gomes, Antônio Augusto Moura da Silva 